\title{
Topical Betamethasone and Hyaluronidase in the Treatment of Phimosis in Boys: a Double-Blind, Randomized, Placebo- controlled Trial
}

\author{
Fabio J. Nascimento, Rodrigo F. Pereira, Jarques L. Silva II, Alessandro Tavares, Antonio C. \\ L. Pompeo
}

Department of Urology, ABC Medical School, Santo Andre, SP, Brazil

\begin{abstract}
Purpose: To compare the efficacy of three different formulations containing Betamethasone Valerate versus placebo in the topical treatment of phimosis. As a secondary goal, we compared the outcomes after 30 and 60 days of treatment. Materials and methods: Two hundred twenty boys aged 3 to 10 years old with clinical diagnosis of phimosis were enrolled. Patients were randomized to one of the following groups: Group 1: Betamethasone Valerate 0.2\% plus Hyaluronidase; Group 2: Betamethasone Valerate 0.2\%; Group 3: Betamethasone Valerate $0.1 \%$ or Group 4: placebo. Parents were instructed to apply the formula twice a day for 60 days and follow-up evaluations were scheduled at 30, 60 and 240 days after the first consultation. Success was defined as complete and easy foreskin retraction.

Results: One hundred ninety-five patients were included at our final analysis. Group $1(\mathrm{~N}=54), 2(\mathrm{~N}=51)$ and $3(\mathrm{~N}=$ 52) had similar success and improvement rates, all treatment groups had higher success rates than placebo( $\mathrm{N}=38)$. After 60 days of treatment, total and partial response rates for Groups 1, 2 and 3 were $54.8 \%$ and 40.1\%, respectively, while placebo had a success rate of $29 \%$. Success and improvement rates were significantly better in 60 days when compared to 30 days.

Conclusions: Betamethasone Valerate $0.1 \%, 0.2 \%$ and $0.2 \%$ in combination with Hyaluronidase had equally higher results than placebo in the treatment of phimosis in boys from three to ten years-old. Patients initially with partial or no response can reach complete response after 60 days of treatment.
\end{abstract}

Key words: phimosis; child; therapy; Betamethasone 17-valerate

Int Braz. J Urol. 2011; 37: 314-319

\section{INTRODUCTION}

Phimosis is an usual condition in which the foreskin cannot be retracted passed the glans penis (1). At birth, there is usually a physiologic phimosis or inability to retract the foreskin because congenital adhesions exist between the prepuce and the glans. By 3 years of age, $90 \%$ of foreskins can be retracted, and less than $1 \%$ of males have phimosis by 17 years of age (2).

In the last decades, the first line treatment was circumcision. In the 90's, many authors introduced topical steroids as a nonsurgical alternative in the treatment of phimosis. Potential advantages included less trauma and lower cost (3), avoidance of anesthesic and surgical complications such as hemorrhage, pain, infection, urinary obstruction and esthetic problems (4).

A variable number of topical steroids have been proposed (5). Triancinolone, Hydrocortisone, Betamethasone, Clobetasone and Monometasone, among others, have been used with varied results and different therapeutic schemes. Reported success rates range from $65 \%$ to almost $90 \%$ (Table- 1 ). However, double-blind, randomized, placebocontrolled trials for the treatment of phimosis are 
Topical betamethasone in the treatment of phimosis

Table 1 - Placebo-Controlled, Randomized Trials with topical steroids in the treatment of phimosis

\begin{tabular}{|c|c|c|c|c|c|c|}
\hline Author / Year & Steroid & $\begin{array}{l}\text { Steroid } \\
\text { potency }\end{array}$ & $\mathbf{N}$ & $\begin{array}{c}\text { Follow-up } \\
\text { (months) }\end{array}$ & $\begin{array}{c}\text { Success Topical } \\
\text { Steroid X } \\
\text { Placebo } \\
\end{array}$ & $\mathbf{p}$ \\
\hline Letendre (1) 2009 & Triamcinolone $0.1 \%$ & $\begin{array}{c}\text { High } \\
\text { (Level 3) }\end{array}$ & 43 & 2 & $76 \% \times 39 \%$ & 0.0086 \\
\hline Espósito (5) 2008 & Mometasone furoate $0.1 \%$ & $\begin{array}{l}\text { Very High } \\
\text { (Level 2) }\end{array}$ & 240 & $20(6-30)$ & $65.8 \%$ X $16.6 \%$ & $<0.0001$ \\
\hline Pileggi (4) 2007 & Mometasone furoate $0.1 \%$ & $\begin{array}{l}\text { Very High } \\
\text { (Level 2) }\end{array}$ & 110 & 2 & $88 \%$ X $52 \%$ & $<0.05$ \\
\hline Lee (12) 2006 & Hydrocortisone & $\begin{array}{c}\text { Low } \\
\text { (Level 7) }\end{array}$ & 78 & 1 & $89.7 \%$ X $20.5 \%$ & $<0.05$ \\
\hline Lund (14) 2005 & Betamethasone & $\begin{array}{l}\text { Very High } \\
\text { (Level 2) }\end{array}$ & 137 & 18 & $74 \% \times 44 \%$ & $<0.05$ \\
\hline Yang (10) 2005 & $\begin{array}{c}\text { Valerate betamethasone } \\
0.06 \% \text { X Clobetasone } \\
\text { butyrate } 0.05 \%\end{array}$ & $\begin{array}{l}\text { Very High } \\
\text { (Level 2) }\end{array}$ & 70 & $\begin{array}{c}4.3 \times 19.1 \\
\text { Weeks }\end{array}$ & $81.3 \%$ X $77.4 \%$ & 0.63 \\
\hline Yilmaz (11) 2003 & Betamethasone $0.05 \%$ & $\begin{array}{l}\text { Very High } \\
\text { (Level 2) }\end{array}$ & 98 & 2 & $68 \%$ X $37.5 \%$ & - \\
\hline Lindhagen (15) 1996 & Propionate clobetasol & $\begin{array}{l}\text { Highest } \\
\text { (Level 1) }\end{array}$ & 30 & 2 & $77 \%$ X $50 \%$ & - \\
\hline Zampieri (13) 2005 & Betamethasone $0.05 \%$ & $\begin{array}{l}\text { Very High } \\
\text { (Level 2) }\end{array}$ & 247 & 6 & $96 \%$ & $<0.001$ \\
\hline Freitas (6) 2006 & $\begin{array}{c}\text { Betamethasone } 0.2 \%+ \\
\text { Hyaluronidase }\end{array}$ & $\begin{array}{l}\text { Very High } \\
\text { (Level 2) }\end{array}$ & 427 & 9 & $92.1 \%$ & - \\
\hline Marques (16) 2005 & Betamethasone $0.5 \%$ & $\begin{array}{l}\text { Very High } \\
\text { (Level 2) }\end{array}$ & 70 & 4 & $94.2 \%$ & - \\
\hline
\end{tabular}

scarce, and very few were found reporting the association between Betamethasone and Hyaluronidase. According to Freitas (6), "Hyaluronidase is an enzyme obtained from bovine testicles that acts on Hyaluronic acid, reducing intercellular viscosity and causing the tissue to become more permeable to the absorption of drugs" (p. 384). Favorito (7) reports that Betamethasone plus Hyaluronidase alters the elastic fibers in the prepuce-glans mucosa, allowing their separation.
Today, reasons for performing circumcision include the recurrent balanoposthitis, pathological phimosis defined as non-retractile, scarred foreskin, persistent physiological phimosis that wasn't resolved by other means after 10 years of age, and Balanitis Xerotica Obliterans (8).

We have designed a double-blind, randomized, placebo-controlled trial evaluating the efficacy of three different formulations containing Betamethasone Valerate and placebo in the topical 
treatment of phimosis and evaluated the complete and partial response rates after 30 and 60 days of treatment.

\section{MATERIALS AND METHODS}

From August 2006 to November 2007, 220 boys aged three to ten years old referred from primary care facilities to our clinic with clinical diagnosis of phimosis were evaluated to entry at our prospective double-blinded study, which was previously approved by the Ethics Committee of the ABC Medical School. Detailed information about treatment options and an Informed Consent were provided to the parents. Exclusion criteria were a) previous treatment; b) signs of current Balanitis or Balanitis Xerotica Obliterans (foreskin or meatus stenosis, hypocromia, foreskin inflammatory process); c) recurrent UTI (surgery is indicated in these cases); d) non-agreement with any of the Informed Consent terms and e) non compliance to treatment procedures.

Patients were randomized to one of the four groups of intervention according to a computer-generated random choice determined by a research assistant: Group 1 (Betamethasone Valerate $0.2 \%$ + Hyaluronidase), Group 2 (Betamethasone Valerate $0.2 \%$ ), Group 3 (Betamethasone Valerate $0.1 \%$ ) or Group 4 (cream placebo group). The four groups format would allow the researcher to determine the optimal formulation containing Betamethasone, considering that the formulations used were the ones available in the market.

All patients were evaluated by the same pediatric urologist on all consultations, to avoid biases in outcome interpretation. On the first consultation, boys were evaluated and phimosis type was assessed according to the Kayaba classification (9) as shown in Table-2. Patients with phimosis type 4 were included because even if this is a lesser degree of the disease, however it is an abnormal condition and needs treatment. The assigned ointment was provided by a research assistant and parents were instructed to use a small amount twice a day for 60 days applying subtle traction on the foreskin (retracting maneuvers). The formulations were specifically designed for the study by the same pharmacy. Follow-up consultations were scheduled at 30 and 60 days. Patients whose treatments were successful were also scheduled to a follow-up consultation 180 days after the first consultation. Compliance with the treatment, adverse effects, complications, and type of phimosis were then assessed. Data collection was performed by a third person based on patients' files.

Cure (success) was defined as complete, easy foreskin retraction with total exposure of the glans after 60 days of treatment. In patients who were not cured, or had partial response were defined as improved degree of phimosis to a better level according to Kayaba's classification. Recurrence was defined as presence of phimosis at 240 post-operative days. For the patients that weren't cured, surgical treatment was performed.

Cure, improvement, complication, and drop-out rates were assessed for each treatment group at each consultation. Statistical analysis was performed using the Fisher's Exact and One-Way ANOVA tests and $p$ values $\leq 0.05$ were considered for statistical differences.

Table 2 - Classification of prepuce type showing presence or absence of tight ring (9).

\begin{tabular}{ll}
\hline Type I & No retraction of prepuce at all \\
Type II & External urethral meatus exposure only \\
Type III & Glans exposure halfway to sulcus of corona \\
Type IV & Glans exposure to above corona at site of preputial adhesion \\
Type V & Easy exposure of whole glans \\
\hline
\end{tabular}




\section{RESULTS}

Two hundred twenty patients were enrolled, of whom 195 were included at our final analysis. Eleven patients $(5 \%)$ were excluded due to noncompliance with the application of the ointment and 16 patients $(7.3 \%)$ were lost to the follow-up but were considered in the analysis before they dropped out. Exclusion and drop-out rates were no different among the four groups of treatment $(p=0.232$ and 0.939 , respectively). Eight children dropped out of treatment before the 30 days consultation, 6 children dropped out between the 30 days and 60 days consultation. Two children who were cured at 60 days did not attend to the follow up consultation, at 180 days.

Pre-treatment analysis of phimosis (9) indicated type I in 128 patients (58.2\%), II in 41 patients $(18.6 \%)$, III in 47 patients $(21.4 \%)$ and IV in 4 patients $(1.8 \%)$

Mean and median age of the patients were 5.1 and 5.0 years old, respectively $(\mathrm{SD}=2.02)$. No difference was observed among the 4 Groups of treatment regarding mean age $(\mathrm{p}=0.088)$ or phimosis type $(\mathrm{p}=0.88)$.

At 30 and 60 days, groups 1, 2, and 3 had higher cure and improvement rates than group 4 (placebo) $(\mathrm{p}<0.001)$ (Table-3). No difference was noticed among groups 1,2 , and 3 related to total and partial response rates after 30 or 60 days $(\mathrm{p}=0.362$ and $\mathrm{p}=0.666$, respectively).

The results for groups 1, 2, and 3 together after 30 days of treatment had a complete response in $31.3 \%$ and partial response in $55.8 \%$. After 60 days, these figures had improved to $54.8 \%$ and $40.1 \%$ respectively $(\mathrm{p}<0.001)$.

Complete and partial response rates according to the pre-treatment phimosis types were similar between the groups, as shown in Table-4 ( $\mathrm{p}=$ 0.074).

Minor complications were observed in 3 patients (1.4\%): 2 balanoposthitis and 1 paraphimosis, which could be manually reduced. These 3 patients could complete the 60-day course of treatment successfully and were considered in the final analysis. Recurrence was observed in 5 cases $(2.4 \%)$. Neither complications nor recurrence rates were related to the group of treatment or to the degree of phimosis $(p=0.134)$.

\section{DISCUSSION}

In the last decade there has been an increasing interest all over the world to use topical steroid as an alternative to the standard circumcision treatment.

Our data shows that betamethasone is effective in the treatment of phimosis, when compared to placebo, regardless of the pre-treatment type, confirming what was observed by Freitas (6). All three groups were superior to placebo at 30 or 60 days after the treatment was initiated. However, the association of Betamethasone plus Hyaluronidase was not superior to Betamethasone alone in $0.1 \%$ or $0.2 \%$ concentrations. This finding shows that the addition of Hyaluronidase does not improve patients' responses, probably indicating that the alteration of the elastic fibers that cures phimosis (6) is due to the steroid alone. However, this study's sample may not be powerful enough to detect differences between $0.1 \%$ and $0.2 \%$ concentrations of Betamethasone.

It is important to point out that the concentration we used was higher than the majority of similar studies. For example, studies by Yang (10) and Yilmaz (11) used Betamethasone at a $0.06 \%$ and $0.05 \%$, while in our study the ointment had at least $0.1 \%$ concentration. We choose a higher concentration, as Freitas et al. (6) did, justified by the perspective of a more effective treatment with a small rate of side effects, since lower concentrations seem to be less effective. Even then, the cure rates were lower than most of the works presented in Table-1, such as Pilegi's (4) and Lee's (12), that reached a cure rate close to $90 \%$ percent. However, in these cases, partial responses (e.g. non complete exposure of the glans or remaining adhesions) were considered success. Therefore, the lower cure rates we achieved was probably due to two aspects: a more strict criteria for cure, that applied only to patients with total exposure of the glans with no reminiscent adherences; and a more strict inclusion criteria, that excluded children younger than three years-old, who present spontaneous resolution of phimosis in $90 \%$ of the cases (2). 
Table 3 - Outcome after 60 days according to treatment Groups (number of patients and percentage).

\begin{tabular}{ccccc}
\hline Outcome at 60 days & & & \\
\hline Groups & Cure & Partial Response & No Change & $\mathrm{n}$ \\
1 & $31(57.4 \%)$ & $19(35.2 \%)$ & $4(7.4 \%)$ & 54 \\
2 & $30(59.0 \%)$ & $19(37.3 \%)$ & $2(3.7 \%)$ & 51 \\
3 & $25(48 \%)$ & $25(48 \%)$ & $2(4 \%)$ & 52 \\
4 & $11(29 \%)$ & $8(21 \%)$ & $19(50 \%)$ & 38 \\
Total & $\mathbf{9 7 ( 4 9 . 8 \% )}$ & $\mathbf{7 1 ( 3 6 . 4 \% )}$ & $\mathbf{2 7 ( 1 3 . 8 \% )}$ & $\mathbf{1 9 5}$ \\
\hline
\end{tabular}

Table 4 - Outcome according to pre-treatment phimosis type.

Outcome after 60 days

\begin{tabular}{ccccc}
\hline Phimosis Type & Cure (\%) & Partial Response (\%) & No Change (\%) & n \\
I & $48(53 \%)$ & $41(46 \%)$ & $1(1 \%)$ & 90 \\
II & $15(54 \%)$ & $12(43 \%)$ & $1(4 \%)$ & 28 \\
III & $8(33 \%)$ & $10(41 \%)$ & $6(25 \%)$ & 24 \\
IV & $3(100 \%)$ & 0 & 0 & 3 \\
\hline
\end{tabular}

The similar cure and improvement rates in all 4 types of phimosis correspond to the work of Zampieri (13), in which the application of betamethasone along with foreskin stretching had similar results to all types of phimosis. Although phimosis type III seems to have a lower cure rate in absolute numbers, it was not statistically different from the other types of phimosis.

According to our findings, it is recommended to extend the treatment period to 60 days, since the results at this time were significantly better than at 30 days. Lund (14) also used a similar treatment period (4 weeks plus another 4 weeks for nonrespondents), reaching an optimal cure rate after 8 weeks of treatment. The same ideal time span was reported by Freitas (6). According to their results and ours, it seems that 60 days (or 8 weeks) are a secure and effective time for this topical treatment before considering surgical alternatives.
Recurrence rates at 240 days $(2.4 \%)$ were lower than other studies with similar methods (8). However, the shorter follow-up period is a limitation of this study, since it could be extended to one year to better assess long term treatment failures.

Dropout rates were lower between 30 and 60 days than before 30 days, indicating that the two month period did not affect treatment compliance. Also, there weren't significant complications in the period between the second and third consultations. The abandonment rates were relative low, since we had $7.3 \%$ of children leaving treatment, while Lund (14) had 18\% of abandonment, although their follow up period was longer. Our data confirms that, since it is a less invasive treatment that has a good rate of cure and improvement, with few complications and good adherence by the family, the topical treatment should be considered as the first therapeutic option. 


\section{CONCLUSIONS}

Betamethasone Valerate at $0.1 \%, 0.2 \%$ and $0.2 \%$ associated with Hyaluronidase had higher cure rates than placebo in the treatment of phimosis in boys aged three to ten years old and is related to a negligible rate of side effects and of recurrence. The association of Betamethasone plus Hyaluronidase had similar results as Betamethasone alone in $0.1 \%$ or $0.2 \%$ concentrations in this period of treatment. Patients who showed no response or partial response after 30 days can show complete response after 60 days of treatment, without compromising the rate of adherence to treatment.

\section{CONFLICT OF INTEREST}

None declared.

\section{REFERENCES}

1. Letendre J, Barrieras D, Franc-Guimond J, Abdo A, Houle AM: Topical triamcinolone for persistent phimosis. J Urol. 2009; 182(4 Suppl): 1759-63.

2. Oster J: Further fate of the foreskin. Incidence of preputial adhesions, phimosis, and smegma among Danish schoolboys. Arch Dis Child. 1968; 43: 200-3.

3. Nobre YD, Freitas RG, Felizardo MJ, Ortiz V, Macedo Jr A: To circ or not to circ: clinical and pharmacoeconomic outcomes of a prospective trial of topical steroid versus primary circumcision. Int Braz J Urol. 2010; 36: 75-85.

4. Pileggi Fde O, Vicente YA: Phimotic ring topical corticoid cream $(0.1 \%$ mometasone furoate $)$ treatment in children. J Pediatr Surg. 2007; 42: 1749-52.

5. Esposito C, Centonze A, Alicchio F, Savanelli A, Settimi A: Topical steroid application versus circumcision in pediatric patients with phimosis: a prospective randomized placebo controlled clinical trial. World J Urol. 2008; 26: 187-90.

6. Garcia de Freitas R, Nobre YD, Demarchi GT, Hachul M, Macedo A Jr, Srougi M, et al.: Topical treatment for phimosis: time span and other factors behind treatment effectiveness. J Pediatr Urol. 2006; 2: 380-5.

7. Favorito LA, Balassiano CM, Costa WS, Sampaio FJB: Treatment of phimosis: structural analysis of prepuce in patients submitted to topical treatment with betamethasone in association with hyaluronidase. Eur Urol Suppl. 2008; 7: 247. Abstract \#704.

8. Johnson PV: Childhood circumcision. Surgery. 2008; 26: 314-16.

9. Kayaba H, Tamura H, Kitajima S, Fujiwara Y, Kato $\mathrm{T}$, Kato T: Analysis of shape and retractability of the prepuce in 603 Japanese boys. J Urol. 1996 ;156: 1813-5.

10. Yang SS, Tsai YC, Wu CC, Liu SP, Wang CC: Highly potent and moderately potent topical steroids are effective in treating phimosis: a prospective randomized study. J Urol. 2005; 173: 1361-3.

11. Yilmaz E, Batislam E, Basar MM, Basar H: Psychological trauma of circumcision in the phallic period could be avoided by using topical steroids. Int J Urol. 2003; 10: 651-6.

12. Lee JW, Cho SJ, Park EA, Lee SJ: Topical hydrocortisone and physiotherapy for nonretractile physiologic phimosis in infants. Pediatr Nephrol. 2006; 21: 1127-30.

13. Zampieri N, Corroppolo M, Camoglio FS, Giacomello L, Ottolenghi A: Phimosis: stretching methods with or without application of topical steroids? J Pediatr. 2005; 147: 705-6.

14. Lund L, Wai KH, Mui LM, Yeung CK: An 18-month follow-up study after randomized treatment of phimosis in boys with topical steroid versus placebo. Scand J Urol Nephrol. 2005; 39: 78-81.

15. Lindhagen T: Topical clobetasol propionate compared with placebo in the treatment of unretractable foreskin. Eur J Surg. 1996; 162: 969-72.

16. Marques TC, Sampaio FJ, Favorito LA: Treatment of phimosis with topical steroids and foreskin anatomy. Int Braz J Urol. 2005; 31: 370-4; discussion 374.

Accepted after revision:

January 04, 2011

\section{Correspondence address:}

Dr. Fábio José Nascimento

Av. Príncipe de Gales, 821 / Anexo 2

Disciplina de Urologia

Santo André, SP, 09060-650, Brazil

Telephone: + 5511 4993-5462

E-mail: fabiojnascimento@terra.com.br 